\title{
SMED Simulation in Optimising the Operating Output of Tandem Press Line in the Automotive Industry using WITNESS Software
}

\author{
A.Q. Basri ${ }^{1}$, N. Mohamed ${ }^{1, *}$, Nelfiyanti ${ }^{1,2}$ and Yusoof $Y^{1}$ \\ ${ }^{1}$ College of Engineering, Universiti Malaysia Pahang, 26600 Pahang, Malaysia \\ 2Department of Industrial Engineering, Faculty of Engineering, Universitas Muhammadiyah Jakarta, 10510 Jakarta, Indonesia
}

\begin{abstract}
The automotive industry is one of the most advanced industries in the world. The demand for vehicles keeps increasing over time, mainly influenced by technology's sophistication and impressive designs. This research is focusing on the production performance of the stamping process in Malaysia's automotive industry. The main issue observed and evidenced in data collected from industry players is that an unacceptably long time is taken in the die/tooling change process, which grossly affects the planned production output. The most significant direct impact on this situation is the increase in operating costs due to additional time taken to meet the planned production output. Therefore, this research aims to establish a new framework that can optimise the efficiency of the dies changeover process, which could lower the overall production cost, which could partially transfer the saving to the consumers. The study was conducted in two stages; the first is on data collection correlates with the automotive stamping premise to create a simulation procedure, and the second is to analyse the current production output using WITNESS simulation. These simulated output data have later been compared to the actual industrial data. Using a systematic dies changeover process, a new alternative framework was proposed. The framework combined single minute exchange of die (SMED), lean tools and simulation to become an integrated single minute exchange of die (ISMED). It shows that the proposed method decreased the changeovers processes from the initial of 1509.5 seconds to 750.75 seconds, then further reduced to 569.75 seconds, with the nett time reduction of $62.2 \%$. The result shows that the daily production output has increased gradually from 1100 pieces to 1500 pieces, further increasing to 2145 pieces. As evidenced in analytical data, it is believed that this new framework can strengthen the total output in the manufacturing process, especially in the manufacturing of automotive stamping parts.
\end{abstract}

\author{
ARTICLE HISTORY \\ Received: $3^{\text {rd }}$ May 2021 \\ Revised: 21 st July \\ Accepted: $12^{\text {th }}$ Sept 2021
}

\section{KEYWORDS}

Automotive industry;

Dies changeover;

SMED;

WITNESS

\section{INTRODUCTION}

The automobile industry is one of the most fascinating and well-known in the world. Since the introduction of domestically produced automobiles in the early 1970s, the industry has attracted a lot of attention, had a big impact, and experienced phenomenal growth in Malaysia [1]. Many parties are similarly impressed by its expansion, which has attracted a diverse range of well-known businesses from around the world, all of which are vying for market share and after-sales maintenance services [2]. Vehicle makers have produced a wide range of models in order to capture the attention of customers and win their hearts. The automobile manufacturers' marketing teams have examined and analysed databases from servers to discover the best items for each market. As a result, potential purchasers have a wide range of models to choose from to meet their diverse requirements.

According to the principle, a large lot size should be adopted in order to lower the cost of installing and upgrading the equipment that runs through the set-up as much as possible [3]. Although traditional methods are used to reduce inventory by producing a large batch, this strategy also contributes to excess inventory by producing more than what is required to meet consumer demand. The theory of mass production is now widely acknowledged to be outmoded [4]. For massproduction manufacturers, the key challenge was to retain price competitiveness and production efficiency. As a result, it has become one of the primary motivations for automakers to focus on price, product quality, product differentiation, and delivery performance at the same time [5]. To support modern manufacturing systems, producers must aim to create a series of processes that allow them to focus on creating value while removing any distractions that slow down output [6].

It is common to detect when the installation of machinery in the production cell in which the provision or exchange of the equipment is an essential milestone towards meeting customer delivery criteria in organisations that utilise a contemporary manufacturing lean production system [7]. Customers with a wide range of needs and low numbers require organisations to make process enhancements that align production capabilities with customer expectations [8]. The time it takes to make the changeover usually determines a producer's ability to meet client delivery deadlines. In general, if the exchange took a lengthy period, a higher group size is required [9]. Another problem for modern manufacturing is meeting the increased demand for a wider range of products or made-to-order items. Product diversification entails the 
production of a variety of commodities in lesser amounts, with the goal of maintaining total productivity [10]. The modern manufacturing trend has seen a growth in product diversity as well as more frequent and smaller product orders. To match this need, businesses must be able to create minor profits and provide new product models on a regular basis [11]. To compete, businesses must identify ways to cut preparation and transition time by eliminating waste and ineffective preparatory operations and converting conversion time into production time [12]. As previously said, the key problem facing the production's turn is to keep it as short as feasible. Single minute exchange of dies (SMED) saves time spent setting up during operation.

SMED is a very popular method that can be used in optimising process time in die changes [13]. SMED is also an important instrument to reduce lot size and provide a faster way to achieve maximum efficiency, which is one of the tools of the lean manufacturing system (LMS) [14]. In an ideal world, the manufacturer could prepare each section separately [15]. Simulation is needed to find out the results of the SMED application for further improvement. SMED itself is a methodology used in reducing delivery time, economical production in small batches in responding to market demand quickly [16]. Therefore, the purpose of this study is to reduce the set-up time at the stamping press line operation faced by the automotive manufacturers. The study focused on the 1000 tonnage tandem press line where most of the medium automotive body parts are produced. This study is very important as the manufacturers need to satisfy the customers' demands within the promised time. It is continuous problems faced by the stamping line on how to reduce the total production hours in completing the targeted production volume. Hence, the SMED methodology was used as a guiding tool to analyse all the activities related to the overall stamping production preparation time in this study.

\section{METHODOLOGY}

A thorough explanation of how the study was conducted is presented, including the industrial problem identification, data collection, working condition analysis, and the improvement of the current problem. This study focuses on the application of Shingo's SMED methodology to reduce non-value-added activities and to reduce the time required to perform changeovers on various dies set/parts number or parts names at automotive stamping operation. Figure 1 shows the research methodology flowchart, which consists of studying the problems associated with procedures in the tandem press line, starting with identifying the main problems on the current die changeover activities, followed by the formation of the ISMED framework and analysis involved during the study.

The data is collected using a series of monitoring procedures based on the SMED method. Observations of time gaps and labour dispersion were also made and focused on during the study. Further, the implications of changeovers time on the operation were implemented through software simulation. The WITNESS software used was to provide a clear picture of the output based on the existing changeovers data. Hence, the critical issues were identified during the changeover processes.

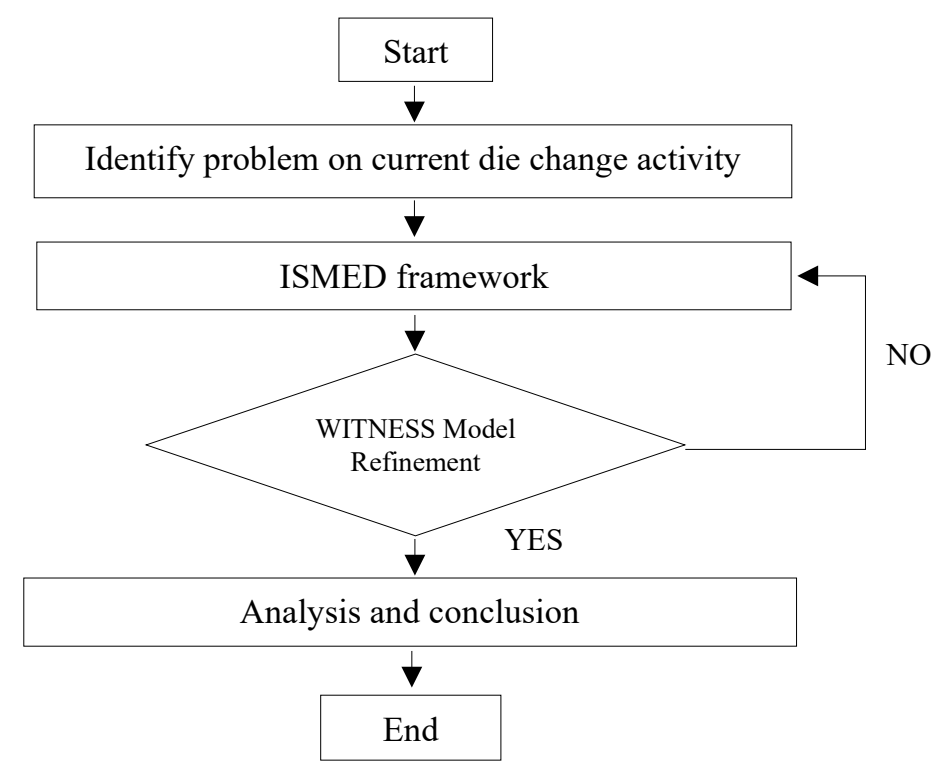

Figure 1. Flowchart of research methodology.

\section{Identification of Problem on Current Die Change Activity}

Production in the stamping operation is very closely associated with the time available during the daily production. The capacity of the press machine is determined on the basis of certain factors such as set-up time, downtime (machine/operation/quality issues) and rest time. Therefore, it is very important to minimise the set-up time, which contributes to the production efficiency during the operation hours. Operational planning has reliable data and monitors the conditions of this stock on a regular basis. Therefore, to maintain a good safety buffer stock and ensure no short supply of parts, the minimum buffer stock of three days per part is imposed. 
Stamping operations hours are often used for daily scheduling. However, there are also constraints on getting a minimum stock of three days per part if there are a high number of downtimes as well as high set-up times. In normal daily production, eight different parts are scheduled to be produced at a particular line. Consequently, there are eight changeover activities to cater for production requirements. During the observation on the manner in which the changeover activities were carried out in this circumstance, the daily operating production is inadequate to meet the production demand. The main contributing factor was due to the high set-up time used during the changeovers process. Accordingly, daily operations were extended to an additional two hours of working time. The direct impact of this situation is the cost of production will increase, as well as prolonged the parts delivery and fatigued workers.

Therefore, the changeover activity needs to be improved at each job or task by identifying the non-value-added activities involved. Thus, a comprehensive analysis focused on multiple lean manufacturing tools, significantly impacts the whole production process. Appropriate lean manufacturing tools such as SMED, VSM, Kaizen, and job standardisation can be used to solve the issues. In addition, there are also some effective analytical methods to solve the non-value-added practices, such as Why's analysis and Fish Bone analysis. However, with existing advanced technology, varieties of simulations software are available to mimic the production processes with detailed explanations. The simulation processes are able to identify the problems and are capable of suggesting the solutions depending on the input by the users.

\section{ISMED Framework Alternative}

ISMED framework is a technique for the arrangement of the changeover issues experienced in the press activity. Thus, ISMED is the new technique to settle the changeover exercises at the stamping shop that focuses on lean manufacturing principles and decision-making as a major foundation. The established ISMED framework is organised into three key elements, as illustrated in Figure 2.

i. Plan: define a problems / a problems overview \& analysis / enhancement programs / validation

ii. ISMED approach: apply VSM, PDCA / 5 Whys analysis tools / work station design / standardization / simulation / SMED.

iii. Implementation of ISMED framework:

- To establish Standard Working Procedure (die change over)

- To implement training program under new S.O.P

- To set up a benchmark press line

- To integrate management view of involvement

- To enchant production plan to increase the number of stroke/day

In this study, the next step after the overall changeover procedure has been defined is the root cause problem identification. Two common root cause analysis methods have been applied namely, Value Stream Mapping (VSM) and Five Why's analysis. The aim of using these methods is to identify any possible root cause problems and their patterns from two different perspectives. Figure 3 describes the VSM in the changeover procedure.

The VSM assessment shown in Figure 3 is divided into four sub-stations based on job/task of changeover actions. Since four machines are required for this tandem processing line, therefore, four sets of equipment for the tandem process are necessary to produce a part. In this VSM assessment, the series of changeover activities from the beginning of the process until it reaches the final process were examined. The root cause identification is then carried out using the Five Why's analysis tool.

The Five Why's analysis is another root cause analysis method applied in this study. This analysis is used to support the VSM analysis presented in the previous section. This analysis is a sequential process of asking 'why' five times in a belief that the actual root cause of the defined problem will appear after asking 'why' five times. However, this description regarding Five Why's analysis procedure is not always necessary, and it depends on how the analysis has been arranged and managed. Meaning that, it is not a significant issue of how many 'why' is being asked, instead of the pattern of answers from a sequence of asking 'why' towards identifying possible root causes contributing to the defined problem.

\section{Simulation Analysis}

WITNESS simulation software is used to identify important processes and to verify actual output based on production data [13]. The WITNESS is used to describe the situation in reducing the waiting time to achieve good performance in terms of consumer satisfaction [17]. WITNESS model simulated the current configuration, including the processes involved in the stamping operation line. All the information required was defined and recorded in accordance with the stamping procedures. The initial results from the current simulation should indicate the effect of the changeover practice currently on the overall line production. All sub-process time has been considered in the total cycle time measurement, including the transfer mechanism of robot loader and human-oriented movement. In running the simulation, data on production planning with normal operating hours were used with the main focus on the changeover impact on the stamping operation. Then, this simulation also aims to determine the results if the ISMED framework was applied to the changeover activities. 


\begin{tabular}{|c|c|c|c|c|}
\hline \multicolumn{2}{|r|}{ PLAN } & \multicolumn{2}{|c|}{ INTEGRATED SMED APPROACH } & $\Rightarrow$ IMPLEMENTATION \\
\hline \multicolumn{2}{|c|}{$\begin{array}{l}\text { Research conduct in the Automotive } \\
\text { Industry; } \\
\text { 1200Tone Tandem Press Line }\end{array}$} & \multicolumn{2}{|c|}{$\begin{array}{ll}\text { i. } & \text { VSM applies to initial data } \\
\text { collection. }\end{array}$} & \multirow{3}{*}{ 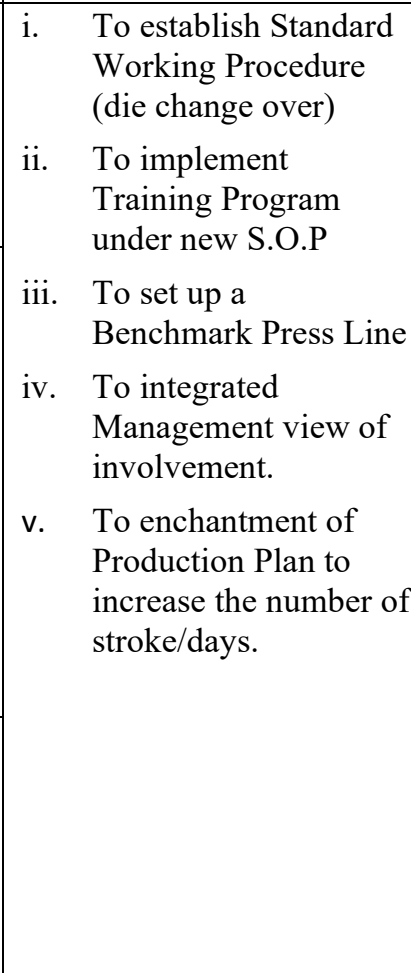 } \\
\hline $\begin{array}{l}\text { Define a } \\
\text { problems }\end{array}$ & $\begin{array}{l}\text { - } \begin{array}{l}\text { Overview research } \\
\text { area. }\end{array} \\
\text { - } \begin{array}{l}\text { Observation of the } \\
\text { actual process. }\end{array} \\
\text { - } \quad \begin{array}{l}\text { Establish a suitable } \\
\text { Check Sheet. }\end{array} \\
\text { - } \quad \begin{array}{l}\text { Schedule activity } \\
\text { changeover. }\end{array} \\
\text { - } \begin{array}{l}\text { Start to collect actual } \\
\text { data. }\end{array}\end{array}$ & $\begin{array}{l}\quad \underline{\text { P: Plan }} \\
\text { A research overall } \\
\text { case study set-up } \\
\text { base on objective; } \\
\text { review } 4 \text { stages } \\
\text { discuss. }\end{array}$ & $\begin{array}{c}5 \text { 'S } \\
5 \text { Why analysis }\end{array}$ & \\
\hline $\begin{array}{c}\text { Review \& } \\
\text { analysis }\end{array}$ & $\begin{array}{l}\text { - Apply the } \\
\text { Conversational SMED } \\
\text { approach. } \\
\text { - Review the result \& } \\
\text { finding a potential area } \\
\text { to improve. }\end{array}$ & $\begin{array}{l}\quad \text { D: Do } \\
\text { To implement a } \\
\text { case study } \\
\text { procedure (base on } \\
\text { critical thinking \& } \\
\text { finding). }\end{array}$ & $\begin{array}{l}\text { Work Station } \\
\text { Design }\end{array}$ & \\
\hline $\begin{array}{c}\text { Enhancement } \\
\text { activity }\end{array}$ & 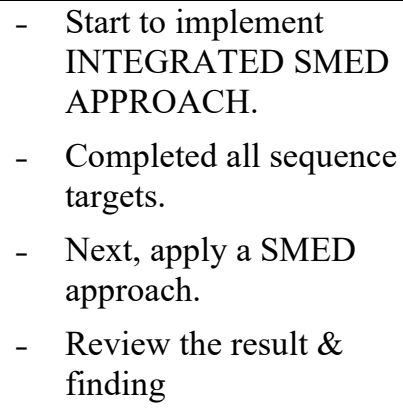 & $\begin{array}{l}\quad \text { C: } \text { Check } \\
\text { To overview all } \\
\text { data collection by } \\
\text { simulation advance } \\
\text { anticipate } \\
\text { judgments [used } \\
\text { WITNESS] }\end{array}$ & Standardisation & \\
\hline Validation & $\begin{array}{l}\text { - } \text { Transfer input at S-2 \& } \\
\text { S-3 into Witness } \\
\text { [simulation software] to } \\
\text { proven data collection } \\
\text { activity. } \\
\text { - } \\
\text { To compare both } \\
\text { results \& discuss a new } \\
\text { finding. }\end{array}$ & $\begin{array}{l}\text { A: Action } \\
\text { To finalise a } \\
\text { discussion finding } \\
\text { \& conclude as } \\
\text { refinement activity } \\
\text { to objective of the } \\
\text { case study. }\end{array}$ & Simulation & \\
\hline
\end{tabular}

Figure 2. ISMED framework model.

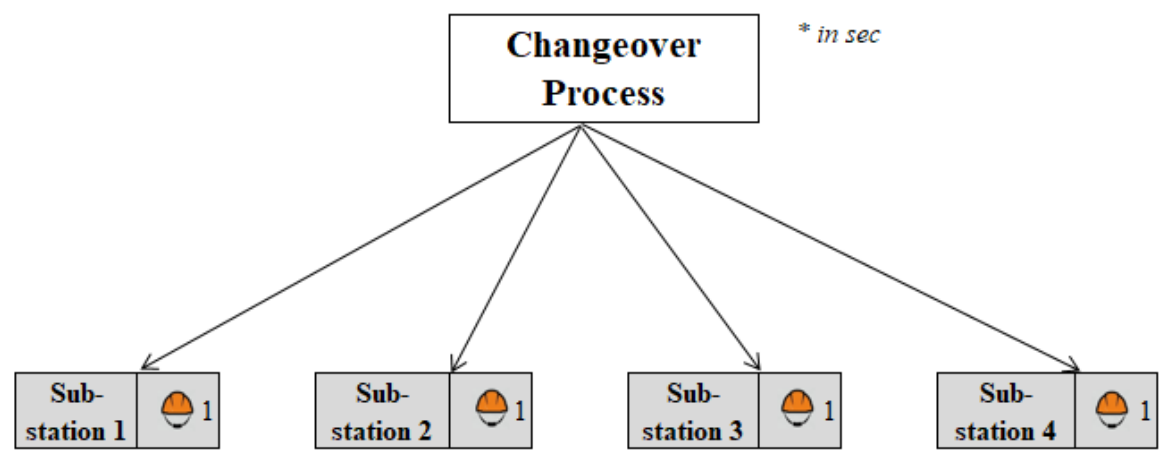

Figure 3. Value stream mapping implemented in changeover procedure. 


\section{RESULTS AND DISCUSSION}

\section{SMED (Conventional) Approach Execution}

The external and internal elements were needed to be recognised in the second stage of the SMED method of the changeover process. Thus, Table 1 classified the steps of the 21 procedures of the changeover processes. Table 1 indicates that external and internal assessments were almost balanced when the number of changeover sequences of work was identified. However, the main influence on the efficiency of SMED implementation would be the time for every job sequence. In the internal elements, observation of improvements should also be determined as non-value-added activities done by workers who were unfamiliar with monitoring of the press line. This would lead to several issues such as high cycle time processes and repeated unsuitable ergonomic factors. Overall, by classifying the external and internal changeover procedures based on the SMED approach, the study can implicitly focus on external activities. Therefore, the amount of time spent in the changeover operations was measured on the basis of job sequences that had not been effectively eliminated.

Table 1. Changeover activity classification on external and internal elements.

\begin{tabular}{|c|c|c|c|}
\hline Seq. & Element (Steps of SMED) & Ext. & Int. \\
\hline 1 & Last good part from previous production & & / \\
\hline 2 & Move previous part run to next operation & & / \\
\hline 3 & Bolster out from the press machine & / & \\
\hline 4 & Get hand tool and loosen (8) bolts & & / \\
\hline 5 & Aside tool and (4) bolts from lower plate & / & \\
\hline 6 & Raise press & / & \\
\hline 7 & To remove dies from bolster to die storage area & & / \\
\hline 8 & Cushion pin setting (base on each parts pin layout) & & / \\
\hline 9 & Waiting for the tamakake operator bring the dies & & / \\
\hline 10 & Place next dies on the bolster and die setting & & / \\
\hline 11 & Machine attachment setting (Vacuum cup). & / & \\
\hline 12 & Get and thread 4 bottom bolts, start threads. & & / \\
\hline 13 & Move control pedestal, move machine slide down to die balancing (slide adjustment) & / & \\
\hline 14 & Upper die; hand tighten (4) top bolts, get hand tool to tighten bolts & / & \\
\hline 15 & Re-install upper die, loose upper dies clamper for dies adjustment (upper and lower) & / & \\
\hline 16 & Attach airline - quick change coupler & / & \\
\hline 17 & Cycle press - validate set-up & / & \\
\hline 18 & Set floor mat and one complete cycle panel produce & & / \\
\hline 19 & Get part for quality checking & & / \\
\hline 20 & Run/aside first part from next run and complete process part quality check & / & \\
\hline 21 & Complete process. Ready to proceed & 1 & \\
\hline
\end{tabular}

The third stage of the SMED method is to separate the external and internal work, focusing on the external work element. In view of the fact that external work elements are activities that workers can do while machines are still in operation and the SMED theory points out that workers need to be more proactive in implementing this changeover procedure aimed at reducing the total reported time. This self-awareness has an indirect impact on the overall success of the changeover. The changeovers were carried out by two workers only at a high-frequency period, and their performance often affects the recorded time of the changeover process

In the fourth and fifth stages of SMED implementation, the internal activities need to be shifted to the external activities. Also, all other activities need to be streamlined. Thus, a careful study was needed to fulfil these stages of SMED, whereby as many as possible to shift the internal activities to external activities. During the study, the main focus was to observe the changeover activities by workers performing work while the press machine was running. In the case of an observation made by the authors, the recorded time of the work sequence is the same if it was noticed. Significantly, by doing this analysis, the efficiency of work handling by workers can also be monitored while they are working. It was discovered during the study, the workers had to wait long time for the job sequence to complete. The direct result would be the complete elimination of idle time during this changeover process.

Table 2 summarises the implementation of the SMED approach for the $\mathrm{C}$ line press. The changeover of job sequences (21 flow of procedure) was divided into four sub-stations to follow the actual changeover processes at the press line. During the assessment, there were four major areas of work in which information on sub-stations was to be implemented by workers involved. By applying the SMED approach, external and internal work distributions at the level of all substations need to be identified and separated. However, all working procedures for sub-station 2, were recognised as internal activities. Meaning that the amount of time recorded can be removed because the work carried out on the situation of the press machines were still in operation. 
Table 2. Summary of changeover time achievement

\begin{tabular}{lccc}
\hline \multirow{2}{*}{ No } & \multirow{2}{*}{ Items } & \multicolumn{2}{c}{ Changeover time } \\
\cline { 3 - 4 } & & Time $(\mathrm{s})$ & Time $(\mathrm{min})$ \\
\hline 1 & Initial changeover & $1,509.50$ & 25.16 \\
2 & SMED approach & 750.75 & 12.51 \\
\hline
\end{tabular}

\section{ISMED Framework Approach}

Detail stamping changeover processes was conducted during the initial study that traced every step from the beginning to the end of the processes. By implementing the VSM method, it had evaluated the existing circumstances with the main focus to eliminate non-value-added steps. With detailed input, the VSM processes path was drawn and studied for possible improvements. The VSM assessment was divided into four sub-stations based on 21 changeover actions as illustrated in Figure 4. Since four machines are required for this tandem processing line, four sets of equipment for the tandem process were necessary for each part. The results of the VSM assessment indicated that the measured time for sub-stations 1 and 2 took longer time compared with substations 3 and 4 . The initial data implied that many areas were not being optimised during changeover activities, and still many non-value-added tasks need thorough analysis in order to achieve more practical and effective assessments.

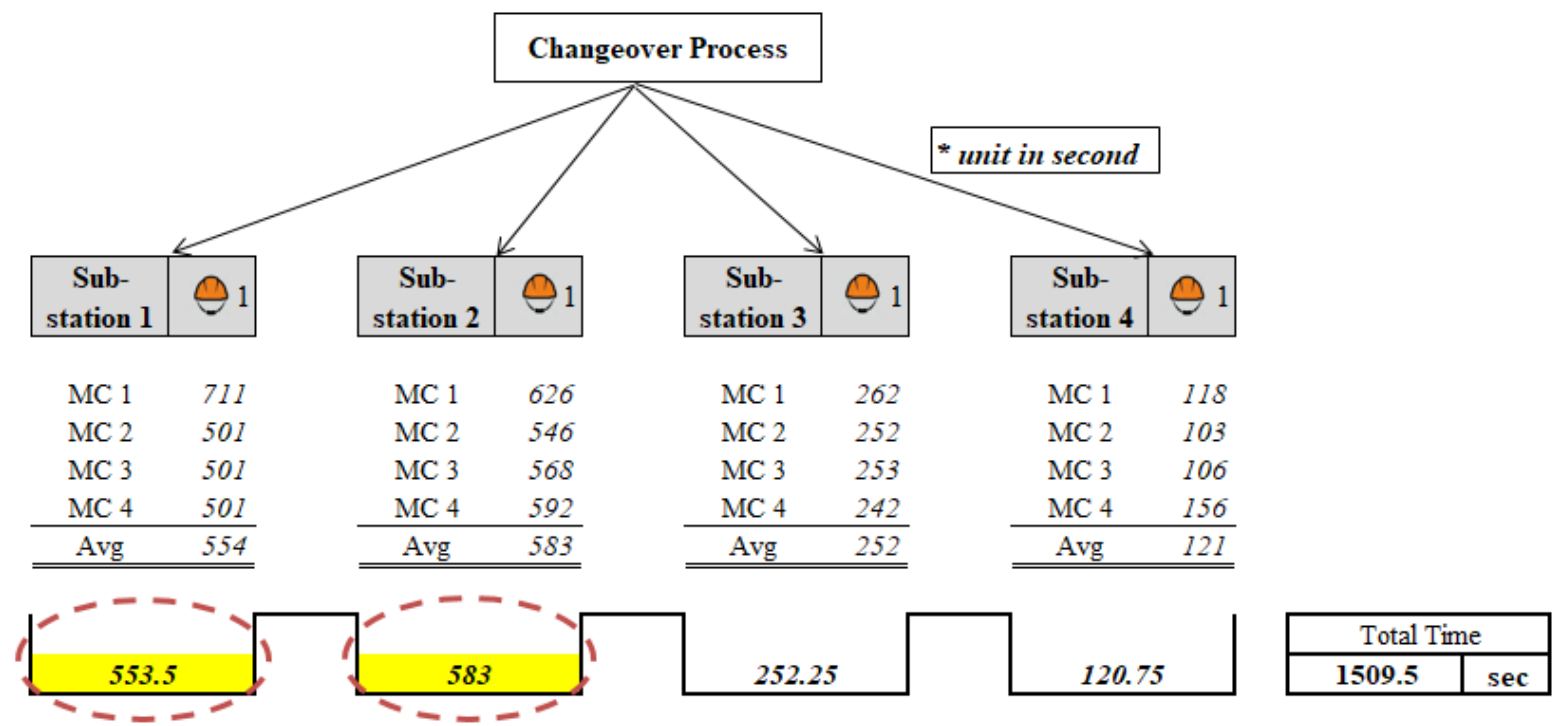

Figure 4. VSM implementation in changeover procedure.

Based on the VSM audit, special attention needed to concentrate on sub-stations with high changeover time, as listed in Table 3. It was identified that sequence no. 4, 7, 8, 11 and 14 were considerably problematic activities that needed to be analysed to define the key factors responsible for problems. However, sub-stations 1 and 2 were the most critical as they covered the first 12 steps of the changeover process. For sub-station 1, the time recorded was 553.5 seconds, while sub-station 2 is 583 seconds. Sub-stations 3 and 4, were less critical as they recorded 252.25 and 120.75 seconds respectively. The total recorded time by the VSM method was exactly the same as the recorded time during the initial changeover initial study, which was 1509.50 seconds.

Once the VSM assessment indicated areas for improvements, the next step of the study was to identify the root cause of the problems. The root cause identification was then carried out by using the five why's analysis. This approach helped to eliminate the symptomatic layers, which could create a problem-solving root causes justification. This approach also helped to be established the sequence between one origin and another root cause item.

Table 3. List of high changeover time.

\begin{tabular}{lcccc}
\hline Sub-Station & Seq. no. & Machine process & SMED step & Time taken (s) \\
\hline 1 & 4 & All Machine & Get hand tool and loosen (8) bolts & 174 \\
2 & 7 & All Machine & To remove dies from bolster to die storage area. & 187 \\
2 & 8 & OP10 & Cushion pin setting (base on each part pin layout). & 109 \\
2 & 11 & All Machine & Machine attachment setting (vacuum cup). & 132 \\
3 & 14 & All Machine & Upper die ; hand tighten (4) top bolts, get hand & 85 \\
\hline
\end{tabular}

\section{Improvement Activities}

It is very important to come up with a new framework for the changeover process at the stamping line. As discussed earlier, five problematic areas had been identified and need to be improved in order to make the productivity of the line at the maximum level. This section focused on the improvement activities to address the identified problems of high-time 
changeover procedure and non-value-added activities. Table 4 listed improvement activities with the intention of optimising the activity appropriate for implementation.

Table 4. Improvement activities conducted according to analysis.

\begin{tabular}{|c|c|c|}
\hline No & Issues & Improvement \\
\hline 1 & $\begin{array}{l}\text { Get hand tools and loosen }(8) \\
\text { bolts. }\end{array}$ & $\begin{array}{l}\text { To design one stop-centre for hand tools storage area. The purpose is easier } \\
\text { for the operator to find and reach. It is also can monitor operator usage. }\end{array}$ \\
\hline 2 & $\begin{array}{l}\text { To remove dies from bolster to } \\
\text { die storage area. }\end{array}$ & $\begin{array}{l}\text { To design a convenient dies storage condition purposely, easier for the } \\
\text { operator to find and reach it back. }\end{array}$ \\
\hline 3 & $\begin{array}{l}\text { Cushion pin setting (base on } \\
\text { each parts pin layout). }\end{array}$ & $\begin{array}{c}\text { To simplify the method of accessing@ references on dies cushion pin } \\
\text { layout. }\end{array}$ \\
\hline 4 & $\begin{array}{l}\text { Machine attachment setting } \\
\text { robot (vacuum cup). }\end{array}$ & $\begin{array}{c}\text { To design one stop-centre for vacuum cup storage area. The purpose is, } \\
\text { easier for the operator to find and reach. It is also can monitoring operator } \\
\text { usage. }\end{array}$ \\
\hline 5 & $\begin{array}{l}\text { Upper die; Hand tighten (4) top } \\
\text { bolts, get hand tool to tighten. }\end{array}$ & $\begin{array}{l}\text { Need to fully study ergonomic issues worker-handling and require re- } \\
\text { designing the purpose of the bolt for automated functioning with cost } \\
\text { impact. }\end{array}$ \\
\hline
\end{tabular}

The ISMED resulted in a significant time reduction in the recorded data, as shown in Table 5. The time on the internal activities was not calculated by the SMED approach as well as the ISMED because of the time used during the machine in operation. Therefore, the time used during internal activities was instantly removed and only focused on external activities. The time recorded in the external element was 569.75 seconds which is equivalent to 9.50 minutes. Table 5 describes the comparison between the initial changeover activity, the SMED approach and ISMED approach. When the SMED approach was introduced, changeover time was reduced from 25.16 minutes to 12.51 minutes, which is $50.3 \%$ of the time reduction. Then, once the ISMED framework was implemented, changeover time was further reduced from 12.51 minutes to 9.50 minutes, which is another $24 \%$ of time reduction. Hence, the total time reduction was from 25.16 minutes to 9.50 minutes, which was significant, at $62.2 \%$. The effectiveness of the ISMED framework had been demonstrated by the results discussed and achieved the objectives of this study.

Table 5. Summary of changeover time achievement.

\begin{tabular}{lccc}
\hline \multirow{2}{*}{ No } & \multirow{2}{*}{ Items } & \multicolumn{2}{c}{ Changeover } \\
\cline { 3 - 4 } 1 & Initial changeover & 1509.50 & Time $(\mathrm{min})$ \\
2 & SMED approach & 750.75 & 25.16 \\
3 & ISMED approach & 569.75 & 12.51 \\
\hline
\end{tabular}

\section{WITNESS Simulations on ISMED Framework}

The purpose of the simulation model is to define any abnormalities in the press system in order to verify problems encountered during the stamping process. This simulation model allows detailed study in order to find possible bottlenecks on the system. The simulation model shown in Figure 6 reproduces in detail the stamping part process of Figure 5. The process started from the blank material first inserted into the 1200T press machines, followed by three 500T machines. These machines representing four different processes according to the dies attached to them. Total cycle time is measured from the blank material insert to the first machine process until the fourth machine completes the finished good parts. All aspects of the transfer mechanisms were included as a sub-job in the pressing process. The simulation model in Figure 6 is in consideration of elements mentioned in Figure 5 with additional input of part production; lot size, part no, part name, model, and cycle time as in Table 6.

Table 6. Production planning on press line based on demand.

\begin{tabular}{lcccc}
\hline Lot Size & Part No & Part Name & Model & Cycle Time \\
\hline 200 & PW932211 & Sill Rear Floor Side Inner LH & aaa & 10 \\
200 & PW932212 & Sill Rear Floor Side Inner RH & aaa & 10 \\
200 & PW932751 & Side Member Front Inner LH & bbb & 10 \\
200 & PW932680 & Side Member Front Inner RH & bbb & 10 \\
300 & PW932258 & Cross Member Dash Lower Inner Center. & bbb & 9.8 \\
400 & PW932129/30 & Cross Member Front Floor Front LH/RH & ccc & 9.8 \\
400 & PW932237/8 & Panel Rear Floor Side LH/RH & ccc & 9.8 \\
400 & PW932299/990 & Support Front Side Member Rear Inner LH/RH & ccc & 10.3 \\
\hline
\end{tabular}




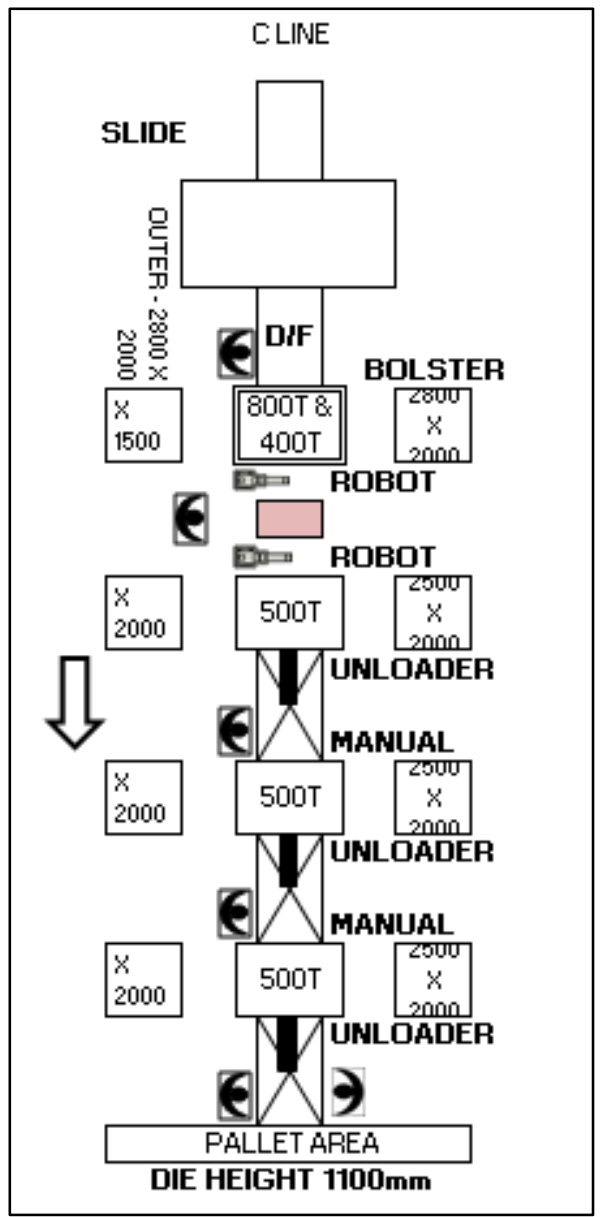

Figure 5. Stamping tandem press operation fundamentals design for WITNESS simulation.

Furthermore, Figure 6 is the simulation of layout design and machines statistics on the ISMED approach implementation using the WITNESS software model. The eight parameter inputs at initial resulting eight outputs with detail simulation shown in Figure 7; with all elements in process initial layout (OP10, OP20, OP30, OP40) and other mentioned in the database.

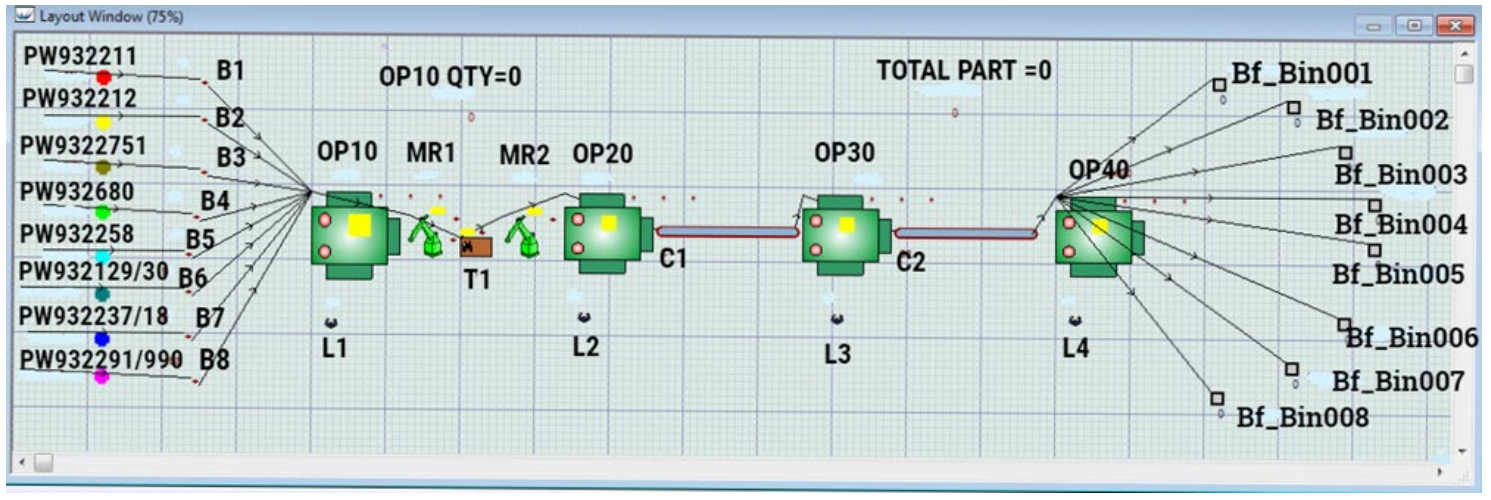

Figure 6. Simulation layout design on ISMED approach implementation.

The shown analysis in Figure 7 and Figure 8 describes the interpretation of the machine statistics and labour skills after the establishment of the ISMED set-up system. In the simulation, the average idle was $33.33 \%$ (reduced by $6.8 \%$ from the initial changeover process), while the busy worker was $71 \%$ on average, which increased $31.7 \%$ from the initial changeover process. This indicates that, in this situation, the rate of productivity of workers had increased and had been satisfactory. 


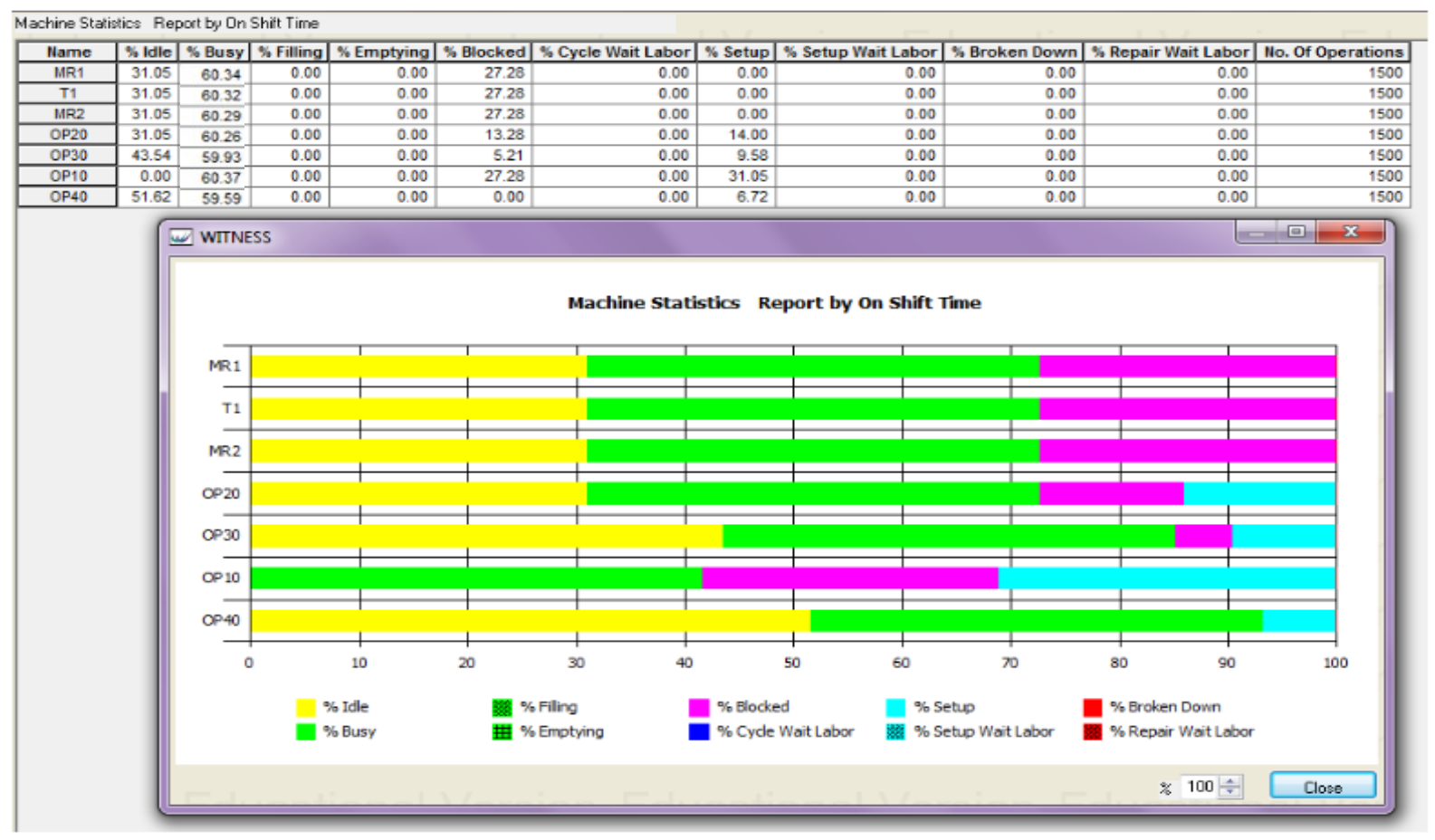

Figure 7. Machines statistic on ISMED approach implementation.

Labor Statistics Report by On Shift Time
\begin{tabular}{|c|r|r|r|r|r|r|r|r|}
\hline Name & Avg Job Ti & \% Busy & \% Idle & No. Of Jobs & No. Of Jobs & Quantity & No. Of Jobs & No. Of Jobs \\
\hline L2 & 0.17 & 62.27 & 37.73 & 2198 & 2197 & 1 & 1 & 0 \\
\hline L1 & 0.23 & 84.31 & 15.69 & 2202 & 2201 & 1 & 1 & 0 \\
\hline L3 & 0.20 & 73.34 & 26.66 & 2186 & 2185 & 1 & 1 & 0 \\
\hline L4 & 0.18 & 64.09 & 35.91 & 2174 & 2173 & 1 & 1 & 0 \\
\hline
\end{tabular}

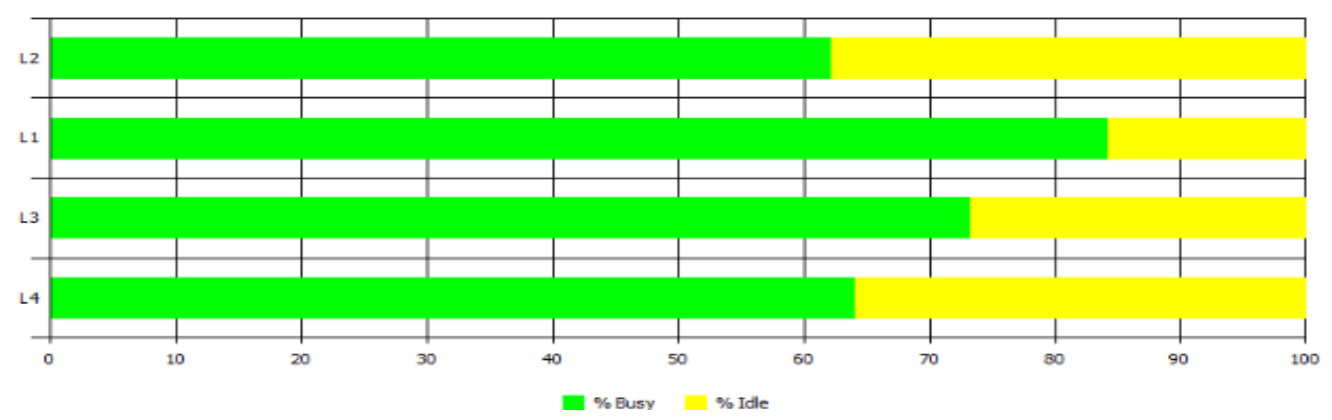

Figure 8. Labour statistics on ISMED approach implementation.

Referring to Figure 9, the ISMED approach showed that the capacity level of this press line throughout normal working hours successfully achieved all eight parts with 2145 pieces of parts as per production planning. Without the implementation of the ISMED framework, the line had just been able to produce five parts within eight hours of production time. They needed extra hours to complete the remaining parts. The ISMED has proven to have positive impacts on stamping production changeover activities.

\section{Simulation Analysis}

In this case study, the usage of WITNESS simulation software required data inputs from changeover specification activities such as production parts planning information, cycle time, parts description, lot size, and the number of direct manpower requirements for the stamping process. The stamping operations where the study was done used planning data of 8 hours/day with two hours spare time for overtime production. This also meant the manpower utilisation was one team for every stamping press line. After considering the numerous downtime activities, the planned capacity at the stamping press line was 2000 pieces as the total output target per day. These inputs or information were the key elements required to project the output of the line situation as the result of the impact of the changeover activities.

Overall, the research had recorded a marked improvement in changeover activities time at the stamping shop department. The study had managed to prove the impact on the planning operations, such as increased in output or production yield in 8-hour working time. In Figure 9, the change activity of the previous section shows the change of activity time from the initial condition to the result of the ISMED application. The previous section showed that the 
recorded changeover time activity was reduced from 1509.5 seconds to 750.75 seconds when the SMED approach was implemented, which was $50.3 \%$ of time reduction. Furthermore, the new framework (ISMED) recorded a reading of 569.75 seconds resulting in a $24 \%$ reduction more. The nett overall result of the changeover time reduction was $62.2 \%$, impacted by ISMED implementation.

\begin{tabular}{|c|c|c|c|c|c|c|c|c|c|c|c|}
\hline Name & Total In & Total Out & Now In & Max & Min & Avg Size & Avg Time & Avg Delay C & Avg Delay T & Min Time & Max Time \\
\hline B1 & 210 & 200 & 10 & 10 & 0 & 9.99 & 28.54 & & & 0.00 & 568.30 \\
\hline$B 2$ & 400 & 200 & 200 & 200 & 0 & 198.33 & 297.50 & & & 33.33 & 566.65 \\
\hline B3 & 400 & 200 & 200 & 200 & 0 & 198.33 & 297.50 & & & 100.63 & 499.35 \\
\hline 84 & 400 & 200 & 200 & 200 & 0 & 198.33 & 297.50 & & & 167.93 & 432.05 \\
\hline 85 & 500 & 300 & 200 & 200 & 0 & 198.33 & 237.99 & & & 33.29 & 314.10 \\
\hline 86 & 600 & 400 & 200 & 200 & 0 & 198.32 & 198.32 & & & 33.29 & 376.39 \\
\hline$B 7$ & 600 & 400 & 200 & 200 & 0 & 198.32 & 196.32 & & & 33.29 & 477.02 \\
\hline$-\mathrm{BE}$ & $-\quad-4 \pi$ & 274 & 200 & 200 & 0 & 198.33 & 251.05 & & & 33.29 & 577.65 \\
\hline Bf_Bin001 & 200 & 0 & 200 & 200 & 0 & 194.07 & 582.21 & & & 0.00 & 598.79 \\
\hline Bf__Bin002 & 200 & 0 & 200 & 200 & 0 & 170.43 & 511.29 & & & 0.00 & 527.87 \\
\hline Bf Bin003 & 200 & 0 & 200 & 200 & 0 & 148.00 & 443.99 & & & 0.00 & 460.57 \\
\hline Bf_Bin004 & 200 & 0 & 200 & 200 & 0 & 125.56 & 376.69 & & & 0.00 & 393.27 \\
\hline Bf_Bin005 & 300 & 0 & 300 & 300 & 0 & 150.53 & 301.05 & & & 0.00 & 325.97 \\
\hline Bf_Bin006 & 400 & 0 & 400 & 400 & 0 & 139.17 & 208.75 & & & 0.00 & 242.00 \\
\hline Bf_Bin007 & 400 & 0 & 400 & 400 & 0 & 72.08 & 108.12 & & & 0.00 & 141.37 \\
\hline Bf_Bin008 & 245 & 0 & 245 & 245 & 0 & 8.33 & 20.40 & & & 0.00 & 40.73 \\
\hline
\end{tabular}

Figure 9. Output of production on SMED approach implementation.

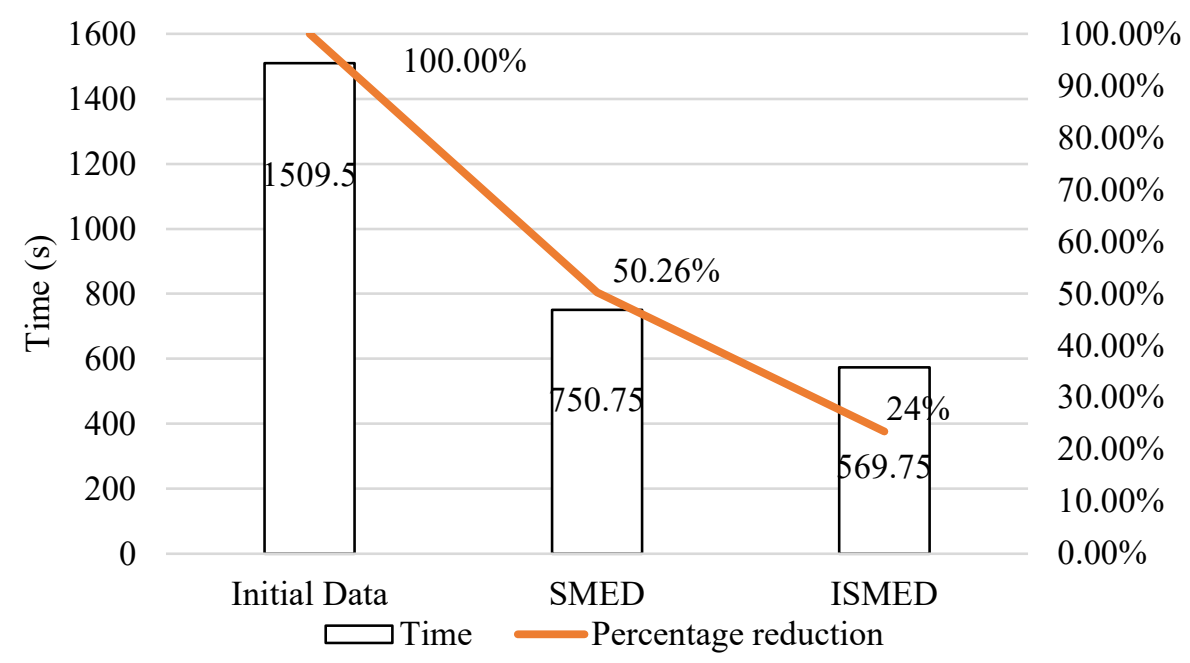

Figure 9. Summary of changeover time recorded.

The validation stages using WITNESS simulation software was meant to study the relation of the changeover time improvements to the actual production output as spelt out in the objective of the research. Based on the maximum target output in eight hours of working time per day was 2000 pieces, equivalent to eight part numbers of production.

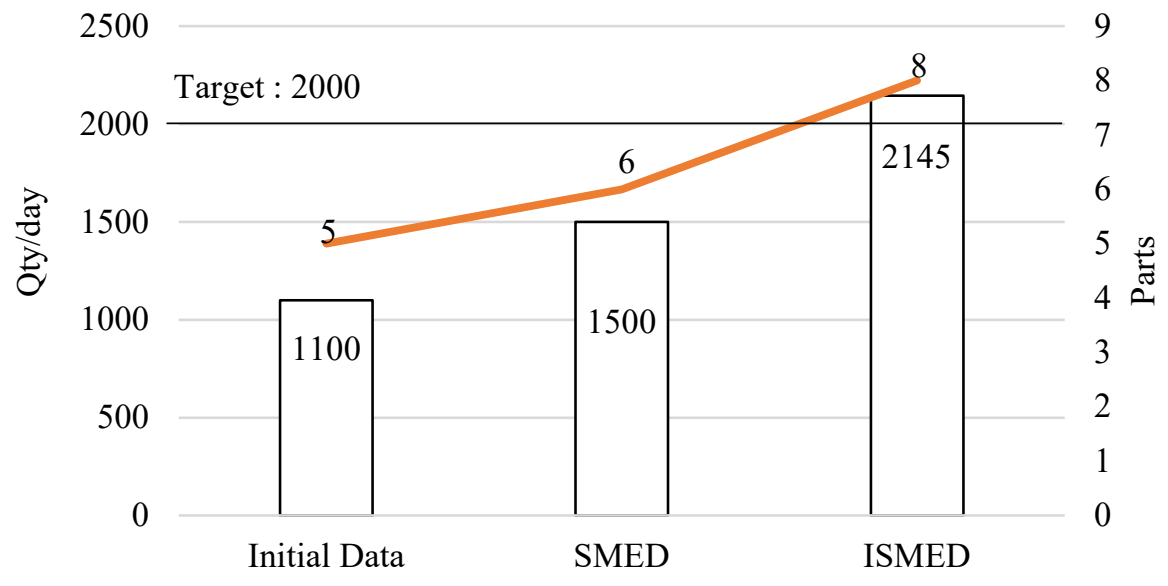

Quantity Stroke $\longrightarrow$ Quantity Part production

Figure 10. Summary of output impact vs changeover time reduction. 
By referring to Figure 10, the first analysis of the initial changeover data was recorded as 1509.5 seconds, which only can produce 1100 pieces/day as suggested by the WITNESS software. Meaning that only five part numbers were able to be produced in a day, even though there should be eight part numbers in actual planning. The remaining parts had to be produced during overtime works and to be continued on the following day. By implementing the SMED approach at the changeover activity, the total time recorded was 750.75 seconds; and the impact on the production operations was an increase in the output value to 1500 pieces/day. This is equivalent to six part numbers being produced in 8 hours of working time. Subsequently, the WITNESS validation was utilised using the changeover data from ISMED framework, which was 569.75 seconds. The WITNESS shows, there was an output increase of 645 pieces from the SMED approach. Hence, the new recorded output of 2145 pieces was equivalent to eight part numbers in eight hours of working time. Consequently, based on this simulation results, it was strongly recommended that the production planning team to plan the daily operations at 2200 pieces/day of total output.

\section{CONCLUSION}

This study focused on improving the current changeover activities at the stamping production line. The study started by observing the current practice and figure out what were the main problems which contributed to the line inefficiency. The study utilised the lean tools and simulation analysis during the investigation and later the improvement processes. The SMED methodology and simulations were used during the first stage of the improvement activities, which involved both internal and external activities of the changeover process. In the second stage, SMED methodology integrated the lean tools, five Why's analysis, and WITNESS simulations to identify the root cause of the problems into a systematic framework in order to reduce the set-up time. The new approach known as ISMED traced all the problems during the changeover activities. Finally, the ISMED framework had shown significant improvement from the initial condition to the latest recorded data. The overall nett result of the changeover time reduction was $62.2 \%$, and parts produced increased from five parts to eight parts, which increased $37.5 \%$. The ISMED framework has proven to be successful and is the novelty of the study. The ISMED framework is workable to other industries, interfacing changeover problematic performances.

\section{ACKNOWLEDGEMENT}

The authors would like to be obliged to Universiti Malaysia Pahang for providing financial assistance under project no. RDU1803166.

\section{REFERENCES}

[1] A. Azizi and T. Manoharan, "Designing a future value stream mapping to reduce lead time using SMED-A case study," Procedia Manuf., vol. 2, pp. 153-158, 2015, doi: doi.org/10.1016/j.promfg.2015.07.027.

[2] S. Mahendran, A. Senthilkumar, and R. Jeyapaul, "Analysis of lean manufacturing in an automobile industry-a case study," Int. J. Enterp. Netw. Manag., vol. 9, no. 2, pp. 129-142, 2018, doi: 10.1504/IJENM.2018.093708.

[3] M. Sugarindra, M. Ikhwan, and MR. Suryoputro, "Single minute exchange of dies as the solution on set-up processes optimisation by decreasing changeover time, a case study in automotive part industry," In IOP Conf. Ser.: Mater. Sci. Eng., 2019, vol. 598, no. 1, doi: 10.1088/1757-899X/598/1/012026.

[4] A. Silva et al., "Implementation of SMED in a cutting line," Procedia Manuf., vol. 51, pp. 1355-1362, 2020, doi: 10.1016/j.promfg.2020.10.189.

[5] A. Huarhua-Machuca et al., "Applying lean techniques to reduce defective products: a case study of an electrode manufacturing company,” In IEEE Int. Conf. Ind. Eng. Eng. Manag. (IEEM), Macao, China, 2019, pp. 541-545, doi: 10.1109/IEEM44572.2019.8978865.

[6] A.A. Karam et al., "The contribution of lean manufacturing tools to changeover time decrease in the pharmaceutical industry a SMED project," Procedia Manuf., vol. 22, pp. 886-892, 2018, doi: 10.1016/j.promfg.2018.03.125.

[7] S.M.O. Vieira and R.B. Lopes, "Improving production systems with lean: a case study in a medium-sized manufacturer," Int. J. Ind. Syst., vol. 33, no. 2, pp. 162-180, 2019, doi: 10.1504/IJISE.2019.102469.

[8] L. Lorente et al., "Applying lean manufacturing in the production process of rolling doors: A case study," J. Eng. Appl. Sci., vol. 13, no. 7, pp. 1774-1781, 2018, doi: 10.3923/jeasci.2018.1774.1781.

[9] P. Tamás, "Examining the possibilities for efficiency improvement of SMED method using simulation modelling," Manuf. Technol., vol. 17, no. 4, pp. 592-597, 2017, doi: 10.21062/ujep/x.2017/a/1213-2489/MT/17/4/592.

[10] M.S. Begam, R. Swamynathan, and J. Sekkizhar, "Current trends on lean management-A review. Int. J. of Lean Thinking, vol. 4, no. 2, pp. 15-21, 2013.

[11] R. Antunes, V. González, and K. Walsh, "Quicker reaction, lower variability: The effect of transient time in flow variability of project-driven production," In Proc. 24 ${ }^{\text {th }}$ Ann. Conf. of the Int. Group for Lean Construction, Boston, USA, 2017, pp. 7382 .

[12] M. Martins et al., "A practical study of the application of SMED to electron-beam machining in automotive industry," Procedia Manuf., vol. 17, p. 647-654, 2018, doi: 10.1016/j.promfg.2018.10.113.

[13] A.Q. Basri et al., "The validation of productivity on the changeover activity at the automotive stamping press line by comparing the embedded SMED framework versus SMED approach: A witness simulation case study," In: IOP Conf. Ser.: Mater. Sci. Eng., 2019, vol. 469, no. 1, doi: 10.1088/1757-899X/469/1/012005.

[14] B.M. Deros et al., "Set-up time reduction in an automotive battery assembly line," Appl. Sci. Eng. Prog., vol. 4, no. 2, pp. 9$13,2011$. 
[15] I.B. da Silva and M. Godinho Filho,"Single-minute exchange of die (SMED): A state-of-the-art literature review," Int. J. Adv. Manuf. Technol., vol. 10, no. 9, pp. 4289-4307, 2019, doi: 10.1007/s00170-019-03484-w.

[16] M. Martins et al., "A practical study of the application of SMED to electron-beam machining in automotive industry," Procedia Manuf., vol. 17, pp. 647-654, 2018, doi: 10.1016/j.promfg.2018.10.113.

[17] A.R. Jeddi et al., "A discreet event simulation in an automotive service context," International Journal of Computer Science Issues (IJCSI), vol. 9, no. 6, pp. 142, 2012. 